This item was submitted to Loughborough's Research Repository by the author.

Items in Figshare are protected by copyright, with all rights reserved, unless otherwise indicated.

\title{
A longitudinal examination of coach and peer motivational climates in youth sport: implications for moral attitudes, well-being, and behavioral investment
}

PLEASE CITE THE PUBLISHED VERSION

http://dx.doi.org/10.1037/a0024934

\section{PUBLISHER}

(c) American Psychological Association

\section{VERSION}

AM (Accepted Manuscript)

\section{LICENCE}

CC BY-NC-ND 4.0

\section{REPOSITORY RECORD}

Ntoumanis, Nikos, lan M. Taylor, and Cecilie Thogersen-Ntoumani. 2019. "A Longitudinal Examination of Coach and Peer Motivational Climates in Youth Sport: Implications for Moral Attitudes, Well-being, and Behavioral Investment". figshare. https://hdl.handle.net/2134/15367. 
This item was submitted to Loughborough's Institutional Repository (https://dspace.lboro.ac.uk/) by the author and is made available under the following Creative Commons Licence conditions.

\section{creative
commons}

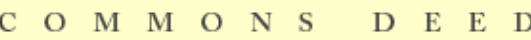

Attribution-NonCommercial-NoDerivs 2.5

You are free:

- to copy, distribute, display, and perform the work

Under the following conditions:

Attribution. You must attribute the work in the manner specified b the author or licensor.

Noncommercial. You may not use this work for commercial purposes.

No Derivative Works. You may not alter, transform, or build upon this work.

- For any reuse or distribution, you must make clear to others the license terms of this work.

- Any of these conditions can be waived if you get permission from the copyright holder.

Your fair use and other rights are in no way affected by the above.

This is a human-readable summary of the Leqal Code (the full license).

\section{Disclaimer 만}

For the full text of this licence, please go to: http://creativecommons.org/licenses/by-nc-nd/2.5/ 
Running head: COACH AND PEER MOTIVATIONAL CLIMATE

A Longitudinal Examination of Coach and Peer Motivational Climates in Youth Sport: Implications for Moral Attitudes, Well-Being, and Behavioral Investment

Nikos Ntoumanis ${ }^{1}$, Ian M. Taylor ${ }^{2}$, and Cecilie Thøgersen-Ntoumani ${ }^{1}$

1. College of Life and Environmental Sciences, University of Birmingham, UK

2. School of Sport, Exercise and Health Sciences, Loughborough University, UK

Address for correspondence:

Dr. Nikos Ntoumanis

College of Life and Environmental Sciences

University of Birmingham

Birmingham

B15 2TT

UK

Tel: + $44(0) 1214147981$

Fax: +44 (0) 1214144121

E-mail: N.Ntoumanis@bham.ac.uk

Manuscript submitted: 07/27/2010

Manuscript resubmitted: 04/18/2011

Author Note

This study was supported by a grant from the Nuffield Foundation (SGS/36273) awarded to the first and third authors. We would like to thank Andrea Livesey, Louise Ewan and Mandy Pollard for their assistance with data collection 
A Longitudinal Examination of Coach and Peer Motivational Climates in Youth Sport: Implications for Moral Attitudes, Well-Being, and Behavioral Investment

Manuscript submitted: 07/27/2010

Manuscript resubmitted: 04/18/2011 


\begin{abstract}
Embedded in achievement goal theory (Ames, 1992; Meece, Anderman \& Anderman, 2006), this study examined how perceptions of coach and peer motivational climate in youth sport predicted moral attitudes, emotional well-being, and indices of behavioral investment in a sample of British adolescents competing in regional leagues. Adopting a longitudinal perspective, measures were taken at the middle and the end of a sport season, as well as at the beginning of the following season. Multilevel modeling analyses showed that perceptions of task-involving peer and coach climates were predictive of more adaptive outcomes compared to perceptions of ego-involving peer and coach climates. Predictive effects differed as a function of time and outcome variable under investigation. The results indicate the importance of considering peer influence in addition to coach influence when examining motivational climate in youth sport.
\end{abstract}

Keywords: motivation, peer influence, coaching, achievement goal theory 
A Longitudinal Examination of Coach and Peer Motivational Climates in Youth Sport: Implications for Moral Attitudes, Well-Being, and Behavioral Investment Organized out-of-school activities are important contexts that help young people negotiate salient developmental tasks and acquire important skills and competencies (Mahoney, Larson, Eccles, \& Lord, 2005). Youth sport is one such context, representing one of the most pervasive and popular free-time activities for boys, and an increasingly popular option for girls in the US and other Western countries (Duda \& Ntoumanis, 2005; Kaestner \& Xu, 2006). The developmental literature underscores the central role that positive relationships with non-familial individuals can have in reducing negative behaviors (e.g., DuBois \& Silverthorn, 2005) and facilitating positive developmental experiences (e.g., Peterson, 2004). Participation in organized sport activities has the potential to teach young people many desired attributes (e.g., self-discipline, moral functioning, cooperation, striving for success) and help them experience psychological well-being (Duda \& Ntoumanis, 2005). However, whether such important outcomes are realized is to a large extent dependent on the type of influence exerted by social-environmental factors (e.g., adults and peers). The purpose of this paper is to examine coach and peer influence in youth sport by adopting an achievement goal theory perspective (Ames, 1992; Nicholls, 1989). Specifically, the paper examines how adolescents' perceptions of the psychological environments created by their coach and peers predict over time their moral attitudes, emotional well-being and ill-being, and their behavioral investment in their sport.

\section{Coach and Peer Motivational Climate in Youth Sport}

The achievement goal theory perspective has been one of the most widely employed conceptual frameworks to study motivation in achievement contexts such as school and sport (Meece et al., 2006; Pintrich 2000). Drawing from a social-cognitive view of motivation, achievement goal theorists argue that understanding variations in behavioral investment, performance, psychological well-being, and affective responses in achievement contexts requires the study of the criteria individuals employ to judge competence and success. The theory focuses on both individual achievement goals (for variations in the conceptualization and operationalization of such goals see Nicholls, 1989; Elliot \& Church, 1997) and the social context or goal structures that shape such individual goals (Ames, 1992). 
The present study focuses on perceptions of goal structures (also called "motivational climate"; Ames, 1992) in the competitive environment of youth sport. Research in this context has predominantly examined the role of coaches in creating task- and ego-involving goal climates (Duda \& Balaguer, 2007). In a task-involving climate the coach emphasizes and rewards individual improvement and effort, offers task variety that matches different ability levels, encourages athletes to take leadership roles and make decisions, and creates heterogeneous ability-based groups that promote cooperation and interaction. In contrast, in an ego-involving climate the coach evaluates and rewards on the basis of normative/comparative ability, encourages inter-individual comparison, forms homogeneous groups based on ability levels, and discourages athlete initiative (Ntoumanis \& Biddle, 1999). Since the early 90s an extensive amount of empirical evidence has been accumulated to demonstrate that a coach task-involving climate, compared to an ego involving climate, is linked to more adaptive behavioral patterns and more positive cognitive and emotional responses among athletes from a variety of competitive levels and cultures (for a review, see Duda \& Balaguer, 2007).

The literature to date in education and sport has mainly focused on adult-created (e.g., coaches and teachers) motivational climate. The potential of peers to transmit task-involving and ego-involving motivational cues has been largely overlooked. This is surprising given that developmental work shows that from late childhood onwards peer influence becomes increasingly important. Wentzel (1999) reviewed evidence in the educational domain which shows that the larger peer group exerts a significant influence on children's motivation, greater than that exerted by dyadic friendships. For example, through cooperative learning activities peers hold each other accountable for certain behaviors, such as offering help and sharing knowledge and expertise. Such behaviors are often encountered in a task-involving climate where students engage in cooperative learning (Ames \& Archer, 1988).

Furthermore, Wentzel argued that peers specify sets of goals that they would like and expect each other to achieve and which are related to peer approval. The role of peers in affecting children’s achievement motivation was also highlighted by Pintrich, Conley, and Kempler (2003). These authors argued that when working toward specific task goals in the classroom, students' achievement goals can be influenced through interactions with peers who may have a "distinct approach" from their teacher toward engaging in the task. Pintrich et al. 
suggested that researchers should examine how peers evoke goals that are distinct from those encouraged by the teacher. The aforementioned achievement goal theory literature sits well with several developmental theories which consider peer environments and their impact on adolescent development. For instance, Vygotsky’s (1978) social development theory proposes that growth is optimal when a cooperative peer environment exists. Social learning theory advocates that adolescents obtain competence-based information by comparing their own performance to that of their peers (e.g., Bandura, 1989). Lastly, Sullivan's (1953) psychiatric view of interpersonal relationships highlights peer relationships as the central mechanism through which adolescents' cooperative and competitive skills are developed.

In sport, Harwood and Swain (2001) examined the distinct influence of coaches, parents, peers, and the tennis national governing body on the development of achievement goals of young elite British tennis players. Using interviews, the authors identified a higher order theme which they called "ego-oriented attitudes of peer group". This theme referred to the excessive emphasis placed by peers on winning. Another higher order theme identified in this study was of a task-involving nature and referred to peer emphasis on skill development and refinement. Harwood and Swain concluded that it is important for researchers to appraise the importance of each significant social agent (including peers) and to measure their independent influence on young athletes’ motivation-related responses.

Vazou, Ntoumanis, and Duda (2006) examined whether peer motivational climate can contribute to the prediction of important motivational experiences of young athletes. Specifically, they were interested to investigate whether, similar to a coach-created climate, a task-involving peer motivational climate would be a better predictor of adaptive motivational outcomes associated with sport participation compared to an ego-involving peer climate. They were also interested to examine whether peer motivational climate can predict these motivational outcomes controlling for the predictive effects of coach climate. Regression analyses showed that perceived task-involving peer climate was the only predictor of physical self-worth. In contrast, perceived ego-involving coach climate emerged as the only predictor of trait anxiety. Enjoyment was positively predicted by peer and, to a lesser extent, coach task-involving motivational climates. These results provided initial, albeit cross-sectional, evidence to suggest that assessing coach motivational climate is not 
sufficient when examining the contextual motivational environment in youth sport, as peers can also be important sources of influence.

However, to date there have been no longitudinal investigations of the effects of coach and peer climate on a range of diverse outcomes in youth sport. This study aimed to address this void in the literature by examining, over a period of one year, how perceptions of coach and peer motivational climate predicted moral attitudes, emotional well-being, and indices of behavioral investment in a sample of British adolescents competing in regional leagues. These concepts have been highlighted as key components of successful growth within widely accepted developmental frameworks and empirical research. For example, positive moral values are an important developmental asset associated with adaptive youth behavior (Benson, 1997). Emotional well-being has also been cited as an important predictor of positive adolescent development (Park, 2004). Finally, investment over time toward a valued goal is a fundamental youth experience necessary for the development of initiative (Larson, 2000).

\section{Moral attitudes, Emotional Well-being and Behavioral Investment in Youth Sport}

Developing a sense of morality and instilling positive values in adolescents is a major political and social objective. Sport is widely assumed to play a significant role in this process by providing a context for learning important virtues (e.g., loyalty, fairness) and resolving moral conflicts (Shields \& Bredemeier, 2007). However, a growing body of empirical literature indicates that sport participation does not automatically lead to character development. In fact, the social environment in which an athlete operates can have profound effects on the development of his/her moral functioning (Kavussanu, Roberts, \& Ntoumanis, 2002). Perceptions of coach task- and ego-involving climate have been linked in the literature with moral functioning in sport. As Kavussanu et al. (2002) noted, when the coach emphasis within a team is on how an athlete's ability compares to that of others (i.e., ego-involving climate), the athletes may try to use any means they have to demonstrate high ability, including engaging in inappropriate actions. Thus, a context that encourages intra-team rivalry is likely to facilitate moral dysfunction. For example, Miller, Roberts, and Ommundsen (2005) showed that perceptions of task-involving coach climate were predictive of more mature moral reasoning of soccer-specific moral dilemmas, 
whereas perceptions of ego-involving climate were predictive of less mature reasoning and the legitimatization of injurious act scenarios.

Perceptions of task- and ego-involving coach climate have also been related to indices of emotional and physical well/ill-being. Coach preoccupation with winning in an ego-involving coaching context may be accompanied by a lack of concern not only for opponents (i.e., low moral functioning) but also for his/her own players' well-being. Indeed studies have shown that variations in perceived coach-created motivational climate can predict whether sport participation can be facilitative or damaging to athletes' welfare. For example, in a sample of junior elite winter sport athletes, Lemyre, Hall, and Roberts (2008) showed that perceptions of a task-involving coach climate at the beginning of a sport season were negative predictors of self-reported burnout (i.e., physical and emotional exhaustion, reduced sense of accomplishment, sport devaluation) at the end of that season. The opposite pattern of relations was found between perceptions of coach ego-involving climate and burnout. These findings seem to extend also to peer motivational climate as similar relations between task- and ego-involving peer climate and burnout were reported by Smith, Gustafsson, and Hassmén (2010). Lastly, Reinboth and Duda (2006) found positive concurrent and prospective relationships between perceptions of task-involving coaching climate and feelings of subjective vitality, an indicator of eudaimonic well-being (Ryan \& Deci, 2001).

Variations in contextual emphasis on task- and ego-involving criteria for competence and success have also been linked with indicators of behavioral investment in youth sport. In a 2-year investigation of persistence among elite young judokas, Le Bars, Gernigon, and Ninot (2009) reported that those who dropped out from national training centers, compared to those who persisted, perceived their coaches and peers as less task-involving and had higher intentions to drop out. This finding makes conceptual sense as a task-involving climate has been linked to a variety of positive psychological experiences in sport which are likely to foster sustained involvement over time (for a review, see Duda \& Balaguer, 2007). A task-involving coach climate has also been associated with higher levels of selfreported effort as well as athlete effort rated by the coach (Vazou et al., 2006).

\section{Aims and Hypotheses}


Spanning a period of one year, the aim of the present study was to examine how perceptions of task- and ego-involving climate, created by both coaches and peers, predict indices of moral attitudes, emotional well-being, and behavioral investment in youth sport. Intra-individual changes, as well as inter-individual and inter-team mean differences in perceptions of motivational climate were modeled as predictor variables. Exploring the different levels of analysis is important because they represent different types of association (i.e., within-person, between-person and between teams).

We hypothesized that changes in perceptions of task-involving climate (egoinvolving climate) would be positively (negatively) associated with changes in pro-social moral attitudes, emotional well-being, and behavioral investment. Negative (positive) relationships were hypothesized between changes in perceptions of task (ego)-involving climate and antisocial moral attitudes and ill-being. We expected that perceptions of both coach and peer climate (task- and ego-involving) would emerge as independent complimentary predictors although we did not hypothesize which outcome variable will be predicted by perceptions of each significant other, due to the dearth of research comparing coach and peer motivational climate.

In addition to examining intra-individual changes, we also investigated whether inter-individual mean differences and inter-team mean differences in perceptions of motivational climate could predict inter-individual/inter-team mean differences in the outcome variables. We made similar hypotheses for inter-individual and inter-team differences. In other words, we expected that higher mean scores on task (ego)-involving perceptions of coach and peer climate would positively (negatively) relate to pro-social attitudes, emotional well-being, and behavioral investment. In contrast, higher mean scores on task (ego)-involving climate perceptions of coach and peer climate were expected to be negatively (positively) associated with antisocial moral attitudes and ill-being.

\section{Method}

\section{Participants and Procedure}

The participants were adolescent athletes aged between 12-16 years from three team sports: soccer, basketball and rugby union. We chose to sample participants over the age of 12 years because there is developmental literature to suggest that at around that age, involvement in youth sport is at its peak (e.g., Telama \& Young, 2000), peer influence is 
salient (Weiss \& Stuntz, 2004), and young people are able to fully understand ego-involving criteria for success (Nicholls, 1989) and thus are able to differentiate between a task- and an ego-involving motivational climate. Although no statistics on ethnicity were collected, the vast majority of the sample was of a White British background. On average, athletes spent about 3 hours per week training in their club $(M=2.88 ; S D=1.49)$ and competed in regional leagues. About half of the participants had four or more years of competitive experience in their sport. Data were collected from this sample at three time points: middle of competitive season ( $n=267$; female $n=45)$, end of competitive season $(n=233$; female $n$ $=53$ ), and beginning of new season $(n=149$; female $n=20)$. The number of participating sport clubs at each time point were 24, 23 and 19, respectively. The drop in the number of participating clubs at the last time point was due to closures resulting from financial recession and the refusal of one club to participate in the last round of data collection.

The first time point was at mid-season to ensure that there was adequate time for a motivational climate to have been established on each team (Smith, Fry, Ethington, \& Li, 2005). Aligned with previous longitudinal studies on perceived motivational climate (e.g., Boyce, Gano-Overway, \& Campbell, 200), we also obtained measures within the last month of the competitive season. The third wave of measurement was at the beginning of the new competitive season because we were interested to ascertain whether athletes who stated at the end of the previous season that they intended to compete for the same club in the following season would actually act on their intentions. Eventually we were not able to test this for a number of reasons, as we explain in the limitations section of the Discussion. Another reason why we chose to have the last measurement wave at the beginning of the following season and not later on (e.g., middle of season) was because we did not want to have a very large imbalance in the length of the intervals among the three assessments as this could introduce analytical complications.

The study received ethical approval from a British University. All participants were treated according to APA ethics guidelines regarding consent, confidentiality, and anonymity of responses. Informed consent was also obtained from coaches and parents. Data collection took place at the clubs in group settings under the supervision of trained research assistants. Questionnaires were matched over time using a coding system to protect anonymity. 


\section{Measures}

Peer motivational climate. The Peer Motivational Climate in Youth Sport

Questionnaire (Peer MCYSQ; Ntoumanis \& Vazou, 2005) taps perceptions of task- and egoinvolving peer climate in youth sport. The scale includes 5 subscales that are subsumed into two higher order factors (Task-involving climate: improvement, relatedness support, effort; Ego-involving climate: intra-team competition, intra-team conflict). The scale includes 21 items that follow the stem "On this team, most athletes...” Responses are indicated on a 7point scale ranging from 1 (strongly disagree) to 7 (strongly agree). Example items are:

“..look pleased when they do better than their teammates” (ego-involving) and “...encourage their teammates to try their hardest” (task-involving). In a series of three validation studies, Ntoumanis and Vazou (2005) showed that the Peer MCYSQ has satisfactory internal reliabilities and both five-factor and hierarchical model solutions have good fit to the data. For the purposes of this study, we used the two global task- and egoinvolving factors in our multilevel regressions.

Coach motivational climate. The Motivational Climate for Youth Sports Questionnaire (MCSYS; Smith, Cumming, \& Smoll, 2008) provides an age-appropriate measure of coach-created motivational climate in youth sport. The scale has 12 items and two factors (i.e., ego-involving and task-involving coach climate). Responses are indicated on a 5-point scale ranging from 1 (not at all true) to 5 (very true). Example items are: "The coach pays most attention to the best players” (ego-involving), and “The coach says that all of us are important to the team’s success” (task-involving). Smith et al. (2008) reported acceptable levels of internal reliability and factorial validity for the MCSYS.

Moral attitudes. We measured four factors (12 items in total), first used together by Lee, Whitehead, Ntoumanis, and Hatzigeorgiadis (2008), to tap prosocial and antisocial attitudes in youth sport. Prosocial attitudes were measured by commitment toward participation (e.g., "It is important to me to be present at all practices”), and respect for conventions (e.g., "When I lose, I congratulate the opponent whoever he or she is”). These subscales were taken from the Multidimensional Sportspersonship Orientation Scale (MSOS; Vallerand, Brière, Blanchard, \& Provencher, 1997). Antisocial attitudes were measured with acceptance of cheating (e.g., "I would cheat if I thought it would help me win.”) and acceptance of gamesmanship (e.g., "It’s a good idea to upset your opponents”), 
taken from the Attitudes to Moral Decision-making in Youth Sport Questionnaire (AMDYSQ; Lee, Whitehead, \& Ntoumanis, 2007). Responses to all subscales were provided on a five-point scale (i.e., 1 = strongly disagree; 5 = strongly agree). Lee et al. (2007) and Vallerand et al. (1997) have provided support for the internal consistency and factorial validity of the MSOS and the AMDYSQ.

Emotional well-/ill-being. We used the subjective vitality scale (SVS; Ryan \& Frederick, 1997) and the Athlete Burnout Questionnaire (ABQ; Raedeke \& Smith, 2007) to tap athletes' well-being and ill-being, respectively. The six-item SVS was employed to assess the extent to which players felt alive and energetic in their daily lives over the preceding month (e.g., "I felt I had a lot of energy”). Responses were provided on a sevenpoint scale (i.e., 1 = strongly disagree; 7 = strongly agree). The ABQ has three subscales and taps reported emotional/physical exhaustion, reduced sense of accomplishment, and devaluation of the sport experience. The three subscales can be averaged to provide an overall measure of perceived burnout (e.g., "I feel so tired from training that I have trouble finding energy to do other things”). Participants responded to the ABQ on a five-point scale (i.e., 1 = strongly disagree; 5 = strongly agree). Research has supported the construct validity as well as the internal reliability of both these scales (e.g., Cresswell \& Eklund, 2006; Gagné, Ryan, \& Bargmann, 2003).

Intention/behavioral investment. The athletes' intention to return to their club in the following sport season was measured once, at the end of the previous sport season (i.e., second time point in our data collection). Two items were used, adapted from Ntoumanis (2005), to measure such intentions (e.g., "I intend to play my sport in this club next season”), using a seven-point response scale (i.e., 1 = strongly disagree; 7 = strongly agree). We also asked the coach of each of the participating clubs to rate each of their athlete’s levels of effort over the previous three months using a 5-point scale (1= no effort at all; $5=$ exceptionally high levels of effort). Adapting a similar scale used by Ntoumanis, the coaches were instructed to base their ratings on how hard their athletes had tried to improve their skills and whether they had given their best when training and competing.

\section{Data Analysis}

Multilevel modeling using the MLwiN software (version 2.10; Rashbash, Steele, Browne, \& Goldstein, 2009) was employed to explore the study hypotheses. This method 
was used because each time measurement of a variable was nested within each individual, and the latter was nested within each team. Multilevel modeling accounts for this hierarchical structure by creating separate equations at each level of analysis (i.e., intraindividual, inter-individual, and inter-team levels in this study). Moreover, multilevel models are particularly useful in longitudinal studies with missing data, as in the present study, because an equal number of observations for all participants is not necessary (Singer \& Willett, 2003). Finally, multilevel modeling allows the effects of individual and group perceptions to be examined simultaneously (Enders \& Tofighi, 2007; Lüdtke, Robitzsch, Trautwein, \& Kunter, 2009).

We first constructed unconditional growth models (i.e., a time variable was included as the only predictor) to explore the temporal pattern of each study variable (with the exception of intention for which a growth rate could not be established as this variable was measured once). Within these unconditional growth models, the slope parameter for time signifies the average linear change over the course of the study for the whole sample. In addition, the inter-individual variance associated with this slope indicates whether participants differed in their rate of change in the study variables.

To examine the extent to which the peer and coach-created motivational climate predicted the outcome variables, a series of linear conditional growth models (Singer \& Willett, 2003) were constructed separately for each outcome variable (except for intentions to continue at the club, because this variable was collected at one time point only). In addition to the linear slope for time (centered at the beginning of the study; i.e., time $=0$ ), the four different facets of the motivational climate (i.e., peer-created task climate, peercreated ego climate, coach-created task climate, and coach-created ego climate) were entered into the Level 1 equation. These variables were centered on each individual's unique mean over time, which enabled for a pure estimation of the intra-individual effects (Enders \& Tofighi, 2007; Lüdtke et al, 2009). As a result, the slope parameters of these variables reflected the extent to which individuals' time-varying perceptions of the motivational climate predicted the outcome variables at the beginning of the study (because the time variable was centered at this time point). To explore whether this relationship changed significantly over the course of the study, time $\times$ predictor interaction terms were also entered into the level 1 equation. If these interaction terms were significant, then the 
relationship between the predictor and outcome variable differed across occasions.

Significant interactions were interpreted using the Johnson-Neyman technique as applied to multilevel modeling (Curran, Bauer, \& Willoughby, 2006). We did not expect the interactions to be significant, as we had no reason to believe that the relationships between individuals' time-varying perceptions of the motivational climate and the outcome variables will vary at different time points.

Next, individuals' perceptions of the four motivational climate variables, averaged across time, were entered into the level 2 equation (i.e., the inter-individual level). These variables were centered on each team's unique mean, therefore, the slope parameters were interpreted as the degree to which individuals' average perceptions of the motivational climate relative to their teammates' perceptions predicted the outcome variables at the beginning of the study. We added these mean scores to ensure that our estimates of withinperson change at level 1 were not confounded by between-person differences (Raudenbush, $\&$ Bryk, 2002). Again, time $\times$ predictor interaction terms were entered into the models to examine whether these relationships changed across measurement occasions (no significant interactions were expected).

When examining group environments, as in the present study, it is essential to include group-level predictor variables in the multilevel equations (Lüdtke et al., 2009). Hence, perceptions of the four motivational climate variables were averaged across time and teams, and entered into the Level 3 equation (i.e., the inter-team level). These variables were centered on the overall mean across all teams, therefore, the slope parameters were interpreted as the extent to which team average perceptions of the motivational climate relative to the grand team mean predicted the outcome variables at the beginning of the study. Again, time $\times$ predictor interaction terms were entered into the multilevel equations to examine whether these relationships changed across measurement occasions (again, no significant interactions were expected). The peer and coach climate scores were converted into $z$ scores before they were entered into the multilevel equations; thus, their regression coefficients are standardized beta coefficients.

Individuals' intentions to continue at the sports club were only measured in the middle of the study (i.e., end of season 1), so it was not possible to create a three-level growth model for this outcome variable. Instead, two-level models were created to explore 
the relationship between the motivational climate and players' intentions. Individuals' perceptions of the four motivational climate variables, centered on each team's unique mean, were entered into the level 1 equation. At level 2, team average perceptions of the four motivational climate variables, centered on the overall mean, were included.

Finally, as estimates of effect size, $R^{2}$ values were calculated. These statistics indicate the proportional amount by which errors of prediction have been reduced from the unconditional growth model to the conditional model at the intra-individual $\left(R_{1}{ }^{2}\right)$, interindividual $\left(R_{2}{ }^{2}\right)$, and inter-team $\left(R_{3}{ }^{2}\right)$ levels.

\section{Results}

\section{Descriptive Statistics and Cronbach's Alpha Coefficients}

Means, standard deviations, and Cronbach's alpha coefficients for each variable at each time point can be seen in Table 1. All scales demonstrated acceptable internal consistency (i.e., $\alpha>.70$ ), with the exception of the commitment scale, which showed moderate internal consistency (i.e., $\alpha>.60$ ). We deemed this acceptable given the relatively few items that comprised the scale. In general, participants reported levels of peer- and coach-created task climate, commitment, respect for conventions, intentions to continue at the club, and vitality above the midpoint of the scale. Participants also reported peer- and coach-created ego climate, and gamesmanship close to the midpoint of the scale. Finally, participants reported levels of burnout and cheating below the midpoint of the scale.

Coaches of the players reported levels of player effort close to the midpoint of the scale.

\section{Temporal Patterns of Change}

The unconditional growth models indicated that the slope parameter for time was significant and negative (indicating a decrease over time) for peer-created ego climate, coach-created task climate, burnout, and coach-rated effort $(\beta=-.10,-.09,-.12$, and -.24 , respectively; all $p<.05$ ). On the other hand, the slope parameter for time was significant and positive (indicating an increase over time) for coach-created ego climate $(\beta=.12, p<$ .05 ). No significant temporal changes were found in peer-created task climate, cheating, gamesmanship, commitment, conventions, and vitality ( $\beta=.06, .02,-.06, .00, .01$, and -.09 , respectively; all $p>.05$ ). However, significant inter-individual variability was observed for vitality $\left(\sigma^{2}=.24, p<.05\right)$, indicating that some participants' scores changed over time despite the lack of significant average change across the whole sample. 


\section{Perceptions of the Motivational Climate as Predictors of the Outcome Variables}

Results of the multilevel modeling analyses are shown in Table 2 and are summarized for each outcome variable below.

\section{Moral Attitudes}

Cheating. At level 1, adolescents' time-varying perceptions of the peer-created task climate negatively predicted cheating at the beginning of the study; however, the significant interaction term indicated that this relationship was not significant at the middle and end of the study. Also, a significant interaction between time and coach-created ego climate revealed that, although the relationship between coach-created ego climate and cheating was not significant at the beginning of the study, a positive relationship existed at the middle and end of the study. Further, this relationship became stronger over the course of the study. At level 2, adolescents’ average perceptions of the coach-created ego climate positively predicted cheating. No significant level 3 relationships were found.

Gamesmanship. At level 1, adolescents' time-varying perceptions of the peercreated task climate negatively predicted gamesmanship at the beginning of the study; however, this relationship was not significant at the middle and end of the study. Also, adolescents' time-varying perceptions of the peer-created ego climate positively predicted gamesmanship. Third, although the relationship between adolescents’ time-varying perceptions of the coach-created ego climate and gamesmanship was not significant at the beginning of the study, a positive relationship existed at the middle and end of the study. Further, this relationship became stronger over the course of the study. At level 2, adolescents' average perception of the peer- and coach-created ego climate positively predicted gamesmanship. At level 3, team average perceptions of the peer-created ego climate positively predicted gamesmanship.

Commitment. At level 1, adolescents’ time varying perceptions of the coach-created task climate positively predicted, and perceptions of peer-created ego climate negatively predicted changes in commitment. At level 2, adolescents' average perceptions of the peerand coach-created task climate positively predicted commitment. No significant level 3 relationships were found.

Conventions. No significant relationships were found at level 1. At level 2, adolescents' average perception of the coach-created task climate positively predicted, and 
perceptions of peer-created ego climate negatively predicted adherence to conventions. At level 3, team average perceptions of the peer-created task and ego climate positively predicted adherence to conventions. Also, a significant interaction between time and team average perceptions of peer-created task climate indicated that the relationship between team average peer-created task climate and adherence to conventions decreased in magnitude over the course of the study and was not significant at the end of the study.

\section{Indices of emotional well-/ill-being}

Burnout. At level 1, adolescents' time-varying perceptions of the peer-created task climate negatively predicted burnout. Additionally, although the relationship between timevarying perceptions of the coach-created ego climate and burnout was not significant at the beginning of the study, a positive relationship existed at the middle and end of the study. Further, this relationship became stronger over the duration of the study. At level 2, adolescents' average perception of the peer-created task climate negatively predicted, and perceptions of the coach-created ego climate positively predicted burnout. At level 3, team average perceptions of the peer-created task climate negatively predicted burnout.

Vitality. No significant relationships were found at level 1. At level 2, adolescents' average perceptions of the peer- and coach-created task climate, as well as coach-created ego climate positively predicted vitality. No significant level 3 relationships were found.

\section{Indices of intention/behavioral investment}

Coach-rated effort. No significant relationships were found at level 1. At level 2, adolescents' average perceptions of the peer-created ego climate negatively predicted coachrated effort. At level 3, team average perceptions of the peer-created task climate positively predicted effort at the beginning of the study, but this relationship was not significant at the middle and end of the study. Also, team average perceptions of the coach-created ego climate positively predicted effort.

Intentions to continue at the club. Adolescents' perceptions of the coach-created task climate positively predicted, and perceptions of the coach-created ego climate negatively predicted intentions. Also, team average perceptions of the coach-created task climate positively predicted intentions. 
Range of effect sizes of each level of analysis. At the intra-individual level the $R_{1}{ }^{2}$ values ranged from .08 to .34 , at the inter-individual level the $R_{2}{ }^{2}$ values ranged from .19 to .51 , and at the inter-team level the $R_{3}{ }^{2}$ values ranged from .44 to .94 .

\section{Discussion}

The purpose of this study was to examine predictors of intra-individual changes, as well as inter-individual and inter-team differences in moral attitudes, emotional well-/illbeing, intentions to continue at the sports club and behavioral investment in youth sport. There is substantial evidence to indicate that engagement in this popular out-of-school context can lead to both positive and negative developmental outcomes (Theokas, 2009). This study shows that task- and ego-involving types of motivational climate in youth sport can be related to variations in the quality of psychological experiences and engagement of young athletes. Further, our study extends previous research by showing that these relationships can be observed over a long period of time (1 year) and with reference to perceived motivational climates created by both coaches and peers. Importantly, the level at which such predictive effects were evident and their duration varied as a function of the variable under investigation.

We looked at the role of coach and peer motivational climate at three levels. The first level examined within-person associations over time, essentially testing whether changes in motivational climate are predictive of changes in the outcomes under investigation. Such changes have not been previously examined in the literature. The second level examined whether average inter-individual differences in perceptions of coach and team climate were predictive of inter-individual differences in the levels of the outcomes under consideration. This type of research question has been extensively pursued in the past literature using ANOVA's and least squares regression analyses. The third level in our analyses looked at inter-team differences in perceptions of motivational climate and whether such differences are predictive of inter-team differences in the examined outcomes. Such analyses have rarely been conducted in the literature, however, Papaioannou, Marsh, and Theodorakis (2004) underscored the importance of exploring such group-aggregated perceptions of the overall team climate. The effect sizes we obtained justified the exploration of all three levels. 
We first examined the predictive effects of perceptions of task- and ego-involving coach and peer climate on antisocial (i.e., acceptance of cheating and gamesmanship) and prosocial (i.e., commitment toward sport participation and respect for conventions) attitudes in youth sport. For both cheating and gamesmanship their intra-individual associations with peer task climate were negative at the beginning of the study but became non-significant thereafter. In contrast, the intra-individual associations between perceptions of coach ego climate and the two antisocial attitudes were non-significant at the beginning but subsequently became significant (in a positive direction). Further, perceptions of peer ego climate were a positive independent predictor of intra-individual changes in gamesmanship across the whole duration of the study. These results suggest that the ego-involving climates created by coaches and peers can be instrumental in the formation of anti-social attitudes. This conclusion is corroborated by the findings at the inter-individual level. Specifically, those with higher average perceptions of peer and coach ego climate reported greater levels of gamesmanship and (as far as coach ego climate is concerned) cheating. These findings extend previous work by Lee et al. (2008) which shows that personal endorsement of ego criteria for success is associated with greater acceptance of antisocial attitudes. Finally, adolescents in teams with higher average perceptions of peer ego climate also reported higher levels of gamesmanship. Hence, the aggregated ego-involving peer atmosphere may contribute to the prediction of antisocial attitudes independently from perceptions of peer climate at the individual level. These team effects are particularly important as they give an insight into the general team atmosphere shared by all team members. Across the three levels of analysis, the results indicate that perceptions of ego-involving coach and peer climate are conducive to the fostering of antisocial attitudes in sport. Our findings make conceptual sense because, as Nicholls (1989) aptly put it, "when winning is everything, it is worth doing anything to win" (p. 133).

In terms of predicting pro-social attitudes, the salient role of a task-involving climate was evident in the results. At the intra-individual level, changes in perceptions of coach task-involving climate were positively associated with changes in commitment. At the interindividual level, differences in adolescents’ average perceptions of coach and peer taskinvolving climate were associated with differences in commitment and (as far as coach task climate is concerned) respect for conventions. There were also small negative effects of ego- 
involving peer climate perceptions at the within- and between-persons levels (on commitment and respect for conventions, respectively). As with anti-social attitudes, these intra- and inter-individual level relationships suggest that perceived peer and coach-created climates have independent relationships with adolescents' pro-social attitudes and should be examined concurrently. In fact, the general pattern of findings indicates that the negative implications of an ego-involved climate are more evident when examining the predictive effects of peer climate.

At the team level, adolescents in teams with higher average scores on task-involving peer climate reported higher levels of respect for convention, although the effect weakened over time. Taken together, the findings for pro-social attitudes are in line with previous research and provide evidence (albeit correlational) for the importance of creating taskinvolving motivational structures that emphasize success through high effort and commitment to sport participation (Treasure \& Roberts, 2001), and teach respect for the game (Gano-Overway, Guivernau, Magyar, Waldron, \& Ewing, 2005). However, our findings extend this proposal by suggesting that these processes can be observed within and across individuals, as well as at the more general team climate level. In contrast, in an egoinvolving climate athletes are less likely to show sportspersonship (Miller et al., 2003) as this may interfere with attempts to win and show superiority over others.

We also examined the predictive effects of perceptions of task- and ego-involving coach and peer climate on two indices of emotional/physical well-being, namely feelings of burnout and vitality. In terms of burnout, perceptions of peer task-involving climate negatively predicted burnout at all three levels of analysis. This implies that a peer group that promotes effort and mastery using self-referenced criteria may serve a protective function against feelings of exhaustion and a reduced sense of accomplishment. In contrast, adolescents' time-varying and average perceptions of coach ego-involving climate were positive predictors (in the former case, the effect was significant at the middle and end of the study) of burnout. These findings replicate previous work that indicates that a motivational atmosphere that both overemphasizes the demonstration of superior ability and devalues the role of individual improvement and effort can be significantly related to perceptions of constant pressure and feelings of depletion of psychological and physical energy resources, even at a high competitive level (Lemyre et al., 2008; Smith et al., 2010). In contrast, as the 
results for vitality indicate, perceptions of a task-involving peer and coach climate (at the between-person level) were associated with high levels of vitality. Similar findings have also been reported by Reinboth and Duda (2006), underscoring the importance of promoting task-involving structures for athletes to feel physically and mentally vigorous and alert while participating in their sport.

We also assessed the predictive effects of perceptions of task- and ego-involving coach and peer climate on two indices of behavioral investment in sport. The first one was athletes' efforts in their sport, as rated by their coach. The analysis showed that there were no significant effects at the intra-individual level. This was possibly due to coaches being unable to accurately assess adolescents' changing level of effort and relying more on their overall evaluations of effort instead. At the inter-individual level, athletes who reported average perceptions of high ego-involving peer climate had lower effort ratings. At the team level, adolescents in teams with high peer task-involving climate had higher effort ratings, but this relationship was significant only at the beginning of the study. Surprisingly, perceptions of coach ego-involving climate were positive predictors of coach-rated effort. It is plausible that coaches who emphasize normative-based success may not be able to accurately assess self-referenced criteria, such as high levels of effort. Overall, the results for effort are not as clear-cut as for the morality and emotional well-being variables. Unfortunately, we did not obtain any athlete self-reported ratings of effort to compare them with those provided by their coaches. Perhaps effort ratings per se are not the most suitable indicators of the quality of behavioral engagement, as it has been shown that effort could be the result of free choice but also the outcome of external contingencies (Ryan, Koestner, \& Deci, 1991). Thus, it is important for future research to distinguish between intrinsically motivated effort and that resulting from internal or external controls and pressure.

We lastly looked at the intentions of the athletes at the end of the sport season (i.e., second measurement wave) to return to their club at the beginning of the following season (i.e., third measurement wave). As this research question was examined at one point in time, no intra-individual changes could have been modeled. At the inter-individual and inter-team levels perceptions of coach task-involving climate were positive predictors of future intentions. Further, perceptions of coach ego-involving climate at the between person level were negative predictors of such intentions. Future intentions was the only variable not 
predicted by peer climate at any level of the analysis. The findings for coach climate are line with past research (e.g., Le Bars et al., 2009), and when viewed in combination with the lack of predictive effects from peer climate, they indicate the potentially important role of coaches for sustaining athlete involvement in sport via creating a motivationally conducive atmosphere.

\section{Conclusions, Limitations and Future Research Directions}

Taken together, the results indicate that perceptions of both coach and peer motivational climate in youth sport can predict variations in moral attitudes, emotional wellbeing and behavioral investment within-adolescents, between-adolescents and across teams. However, predictive effects differed as a function of measurement wave and outcome variable under investigation. Future work is needed to explore potential reasons for such variations. The limited longitudinal work on coach motivational climate has not addressed the question of why the predictive effects of this type of motivational environment might vary in strength over time. Work on peer motivational climate from an achievement goal perspective is still in its infancy and many research questions await to be explored (Ntoumanis, Vazou, \& Duda, 2007), in particular as to the origins of peer motivational climate and how the coach climate might set the tone for peer interactions.

A limitation of our study was that the findings, although longitudinal, were correlational and no causal inferences can be drawn as to the relationships between motivational climates and indices of morality, psychological well-being and behavioral investment. However, our findings are in line with theoretical predictions regarding the causal impact of different motivational climates on these outcome variables (e.g., Ames, 1992; Duda \& Ntoumanis, 2005; Meece et al., 2006). Further, our findings are line with experimental evidence stemming from manipulations of motivational climates in classroom, physical education and sport settings (e.g., Maehr \& Midgley, 1991; Smith, Smoll, \& Cumming, 2007; Wallhead \& Ntoumanis, 2004).

Another limitation of this study was that perceptions of parental climate were not included in our analyses. There is evidence, albeit limited compared to the empirical database on coach motivational climate, that parental task- and ego-involving motivational climates can also be predictors of important outcomes in youth sport (White, 2007). Although we had initially included measures of paternal and maternal motivational climate 
in our questionnaire pack, many of the clubs we approached objected to the administration of such measures as they felt that parents were being evaluated. Even though parental influence is important in youth sport, this is probably more the case in the US that has a more extensive out-of-school club structure than the UK. To the best of our knowledge, there is no comparative cross-cultural research on this issue. Incorporating perceptions of parental climate in future research would extend the scope of the present study. Given the practical constraints faced by our research, such an objective could be achieved by organizing information workshops for parents and coaches about motivational climate in youth sport, in addition to providing information sheets and consent forms. An additional shortcoming of our study was that it relied heavily on self-reports, with the exception of coach ratings of effort, and thus to some extent our findings are subject to potential influences of shared method variance (a common problem in the motivational climate literature). Future longitudinal research in this area will do well to obtain records of objective markers of well-being (e.g., cortisol levels), morality (e.g., number of times athletes have been disciplined by game officials), and behavior. Nevertheless, there is evidence to suggest that task-involving situations are associated with objective markers of behavioral persistence, more prosocial behaviors and less antisocial behaviors (e.g., Ntoumanis, 2005, Sage \& Kavussanu, 2007), thus, it is unlikely that our findings can be solely attributed to shared method variance. In our study it was not possible to test the “intention-drop out” link in our study, as we could not ascertain whether the athletes who did not complete the last wave of assessments had dropped out from their club or did not complete the questionnaire pack for other reasons. This problem was due to a combination of reasons such as refusal from some clubs to provide this information or even to continue their involvement with our study, and the closure of other clubs due to financial reasons.

Despite the aforementioned limitations, this study makes a unique contribution to the literature by examining the concurrent predictive effects of peer and coach motivational climate on a variety of important variables in youth sport at three different levels of analysis over a 12-month period. Future research can build upon this study by incorporating measures of coach and peer climate as provided by coaches and peers (e.g., in the latter case young athletes can be asked whether they highlight ego- or task-involving criteria when they interact with fellow athletes) and examine variations between athletes’ perceptions and 
coaches and peers' reports of the motivational climate they create. Similar work in school physical education has identified large discrepancies in ratings of teacher climate, when student and teacher ratings of this type of climate were compared (Taylor \& Ntoumanis, 2007). From an achievement goal perspective, it is how motivational climate is perceived (as opposed to what teachers themselves report they do) that primarily determines its consequences (Ames, 1992; Meece et al., 2006), however, this has yet to be empirically determined in youth sport with respect to coach and peer climate. 


\section{References}

Ames, C. (1992). Classrooms: Goals, structures, and student motivation. Journal of Educational Psychology, 84, 261-271. doi:10.1037/0022-0663.84.3.261

Ames, C., \& Archer, J. (1988). Achievement goals in the classroom: Students’ learning strategies and motivation processes. Journal of Educational Psychology, 80, 260-267. doi:10.1037/0022-0663.80.3.260

Bandura, A. (1989). Social cognitive theory. In R. Vasta (Ed.), Annals of child development. Vol. 6. Six theories of child development (pp. 1-60). Greenwich, CT: JAI Press.

Benson, P. L. (1997). All kids are our kids: What communities must do to raise caring and responsible children and adolescents. San Francisco: Jossey-Bass.

Boyce, B., A., Gano-Overway, L.A., \& Campbell, A. L. (2009). Perceived motivational climate's influence on goal orientations, perceived competence, and practice strategies across the athletic season. Journal of Applied Sport Psychology, 21, 381 - 394. doi:10.1080/10413200903204887

Cresswell, S., Eklund, R. (2006). The convergent and discriminant validity of burnout measures in sport: A multi-trait/multi-method analysis. Journal of Sports Sciences, 24, 209-220. doi:10.1080/02640410500131431

Curran, P. J., Bauer, D. J., \& Willoughby, M. T. (2006). Testing and probing interactions in hierarchical linear growth models. In C. S. Bergeman \& S. M. Boker (Eds.), The Notre Dame Series on Quantitative Methodology: Vol. 1. Methodological issues in aging research (pp. 99-129). Mahwah, NJ: Erlbaum.

DuBois, D. L., \& Silverthorn, N. (2005). Natural mentoring relationships and adolescent health: Evidence from a national study. American Journal of Public Health, 95, 518524. doi:10.2105/AJPH.2003.031476

Duda, J. L., \& Balaguer, I. (2007). The coach-created motivational climate. In D. Lavalee \& S. Jowett (Eds.) Social Psychology of Sport (pp. 117-143). Champagne, IL: Human Kinetics.

Duda, J. L., \& Ntoumanis, N. (2005). After-school sport for children: Implications of a taskinvolving motivational climate. In J. L. Mahoney, R. Larson, \& J. Eccles (Eds.), Organized activities as contexts of development: Extracurricular activities, after-school and community programs (pp. 311-330). Mahwah, NJ: Erlbaum. 
Elliot, E.S., \& Church, M.A. (1997). A hierarchal model of approach and avoidance achievement motivation. Journal of Personality and Social Psychology, 72, 218-232. doi:10.1037/0022-3514.72.1.218

Enders, C. K. \& Tofighi, D. (2001). Centering predictor variables in cross-sectional multilevel models: A new look at an old issue. Psychological Methods, 12, 121-138. doi:10.1037/1082-989X.12.2.121

Gagné, M., Ryan, R. M., \& Bargmann, K. (2003). Autonomy support and need satisfaction in the motivation and well-being of gymnasts. Journal of Applied Sport Psychology, 15, 372-390. doi:10.1080/714044203

Gano-Overway, L. A., Guivernau, M., Magyar, T. M., Waldron, J. J., Ewing, M. E. (2005). Achievement goals and perceptions of the motivational climate on sportspersonship: Individual and team effects. Psychology of Sport and Exercise, 6, 215-232. doi:10.1016/j.psychsport.2003.11.001

Harwood, C. \& Swain, A. B. J. (2001). The development and activation of achievement goals in tennis: I. Understanding the underlying factors. The Sport Psychologist, 15, 319-341.

Kaestner, R. Xu, X. (2006). Effects of Title IX and sports participation on girls' physical activity and weight. Advances in Health Economics and Health Services Research, 17, 79-111. doi:10.1016/S0731-2199(06)17004-1

Kavussanu, M., \& Roberts, G., \& Ntoumanis, N. (2002). Contextual influences on moral functioning of college basketball players. The Sport Psychologist, 16, 347-367.

Maehr M, \& Midgley C. (1991). Enhancing student motivation: A schoolwide approach. Educational Psychology, 26, 399-427.doi:10.1207/s15326985ep2603\&4_9

Larson, R. (2000). Toward a psychology of positive youth development. American Psychologist, 55, 170-183. doi:10.1037/0003-066X.55.1.170

Le Bars, H., Gernigon, C., \& Ninot, G. (2009). Personal and contextual determinants of elite young athletes' persistence or dropping out over time. Scandinavian Journal of Medicine and Science in Sports, 19, 274-285. doi:10.1111/j.1600-0838.2008.00786.x

Lee, M. J., Whitehead, J. \& Ntoumanis, N. (2007). Development of the Attitudes to Moral Decisions in Youth Sport Questionnaire. Psychology of Sport and Exercise, 8, 369-392. doi:10.1016/j.psychsport.2006.12.002 
Lee, M. J., Whitehead, J., Ntoumanis, N., \& Hatzigeorgiadis, A. (2008). Relationships between values, achievement orientations, and attitudes in youth sport. Journal of Sport and Exercise Psychology, 30, 588-610.

Lemyre, P. N., Hall, H. K., \& Roberts, G. C., (2008). A social cognitive approach to burnout in elite athletes. Scandinavian Journal of Medicine and Science in Sports, 18, 221-224. doi:10.1111/j.1600-0838.2007.00671.x

Lüdtke, O., Robitzsch, A., Trautwein, U., \& Kunter, M. (2009). Assessing the impact of learning environments: How to use student ratings of classroom or school characteristics in multilevel modeling. Contemporary Educational Psychology, 34, 120131. doi:10.1016/j.cedpsych.2008.12.001

Mahoney, J. L., Larson, R. W., Eccles, J. S., \& Lord, H. (2005). Organized activities as developmental contexts for children and adolescents. In J. L. Mahoney, R. W. Larson, \& J. S. Eccles (Eds.). Organized activities as contexts of development: Extracurricular activities, after-school and community programs (pp. 4-22). Mahwah, NJ: Lawrence Erlbaum Associates.

Meece, J. L., Anderman, E. M. \& Anderman, L. H. (2006). Classroom goal structures, student motivation, and academic achievement. Annual Review of Psychology (Vol. 57, pp. 487-504). Chippewa Fall, WI: Annual Reviews. doi:10.1146/annurev.psych.56.091103.070258

Miller, B. W., Roberts, G. C., \& Ommundsen, Y. (2004). Effect of motivational climate on sportspersonship among competitive youth male and female football players. Scandinavian Journal of Medicine and Science in Sports, 14, 193-202. doi:10.1111/j.1600-0838.2003.00320.x

Nicholls, J. G. (1989). The competitive ethos and democratic education. Cambridge, MA: Harvard University Press.

Ntoumanis, N. (2005). A prospective study of participation in optional school physical education based on self-determination theory. Journal of Educational Psychology, 97, 444-453. doi:10.1037/0022-0663.97.3.444

Ntoumanis, N., \& Biddle, S. J. H. (1999). A review of motivational climate in physical activity. Journal of Sport Sciences, 17, 643-665. doi:10.1080/026404199365678 
Ntoumanis, N., \& Vazou, S. (2005). Peer motivational climate in youth sport: Measurement development. Journal of Sport \& Exercise Psychology, 27, 432-455.

Ntoumanis, N., Vazou, S., \& Duda, J. L. (2007). Peer-created motivational climate. In S. Jowett \& D. Lavallee (Eds.) Social psychology in sport (pp. 145-156). Champaign, IL: Human Kinetics.

Papaioannou, A., Marsh, H. W., \& Theodorakis, Y. (2004). A multilevel approach to motivational climate in physical education and sport settings: An individual or a group level construct? Journal of Sport and Exercise Psychology, 26, 90-118.

Park, N. (2004). The role of subjective well-being in positive youth development. Annals of the American Academy of Political and Social Science, 591, 25-39. doi:10.1177/0002716203260078

Peterson, C. (2004) Positive social science, Annals of the American Academy of Political and Social Science, 591, 186-201. doi:10.1177/0002716203260100

Pintrich, P. R. (2000). Multiple goals, multiple pathways: The role of goal orientations in learning and achievement. Journal of Educational Psychology, 92, 544-555. doi:10.1037/0022-0663.92.3.544

Pintrich, P. R, Conley, A., \& Kempler, T. (2003). Current issues in achievement goal theory and research. Educational Research, 39, 319-337.

Raedeke, T.D. \& Smith, A. (2001). Development and preliminary validation of a measure of athlete burnout. Journal of Sport and Exercise Psychology, 23, 281-306.

Rashbash, J., Steele, F., Browne, W. J., \& Goldstein, H. (2009). A user's guide to MLwiN (Version 2.10). Bristol, UK: University of Bristol.

Raudenbush, S. W., \& Bryk, A. S. (2002). Hierarchical linear models: Applications and data analysis methods ( $2^{\text {nd }}$ ed.). Thousand Oaks, CA: Sage.

Reinboth, M., \& Duda, J. L. (2006). Perceived motivational climate, need satisfaction and indices of well-being in team sports: A longitudinal perspective. Psychology of Sport and Exercise, 7, 269-286. doi:10.1016/j.psychsport.2005.06.002

Ryan, R. M., \& Deci, E. L. (2001). On happiness and human potentials: A review of research on hedonic and eudaimonic well-being. Annual Review of Psychology, 52, 141-166. doi:10.1146/annurev.psych.52.1.141 
Ryan, R. M., Koestner, R., \& Deci, E. L. (1991). Varied forms of persistence: When freechoice behavior is not intrinsically motivated. Motivation and Emotion, 15, 185-205. doi:10.1007/BF00995170

Sage, L., \& Kavussanu, M. (2007). The effects of goal involvement on moral behavior in an experimentally manipulated competitive setting. Journal of Sport and Exercise Psychology, 29, 190-207

Shields, D. L. L., \& Bredemeier, B. J. L. (2007). Advances in sport morality research. In G. Tenenbaum \& R. C. Eklund (Eds.), Handbook of sport psychology (3rd ed., pp.662684). Indianapolis, IN: Wiley.

Singer, J. D., \& Willett, J. B. (2003). Applied longitudinal data analysis: Modeling change and event occurrence. Oxford, UK: Oxford University Press. doi:10.1093/acprof:oso/9780195152968.001.0001

Smith, A. L., Gustafsson, H., \& Hassmén, P. (2010). Peer motivational climate and burnout perceptions of adolescent athletes. Psychology of Sport \& Exercise, 11, 453-460. doi:10.1016/j.psychsport.2010.05.007

Smith, R. E., Cumming, S. P., \& Smoll, F. L. (2008). Measurement of motivational climate in youth sports: The Motivational Climate Scale for Youth Sports. Journal of Applied Sport Psychology, 20, 116-136. doi:10.1080/10413200701790558

Smith, R. E., Smoll, F. L., \& Cumming, S. P. (2007). Effects of a motivational climate intervention for coaches on young athletes' sport performance anxiety. Journal of Sport and Exercise Psychology, 29, 39-59.

Smith, S. L., Fry, M. D., Ethington, C. A. \& Li, Y. (2005). The Effect of female athletes' perceptions of their coaches' behaviors on their perceptions of the motivational climate. Journal of Applied Sport Psychology, 17, 170 - 177. doi:10.1080/10413200590932470 Sullivan, H. S. (1953). The interpersonal theory of psychiatry. London: Tavistock.

Taylor, I., M. \& Ntoumanis, N. (2007). Teacher motivational strategies and student selfdetermination in physical education. Journal of Educational Psychology, 99, 747-760. doi:10.1037/0022-0663.99.4.747

Telama, R., Yang, X. (2000). Decline of physical activity from youth to young adulthood in Finland. Medicine and Science in Sports and Exercise, 32, 1617-1622. doi: 01959131/00/3209-1617/0 
Theokas, C. (2009). Youth sport participation-A view of the issues: Introduction to the special section. Developmental Psychology, 45, 303-306. doi:10.1037/a0015042

Vallerand, R. J., Brière, N. M., Blanchard, C., \& Provencher, P. (1997). Development and validation of the multidimensional sportspersonship orientations scale. Journal of Sport and Exercise Psychology, 19, 197-206.

Vazou, S., Ntoumanis, N., \& Duda, J. L. (2006). Predicting young athletes’ motivational indices as a function of their perceptions of the coach- and peer-created climate. Psychology of Sport \& Exercise, 7, 215-233. doi:10.1016/j.psychsport.2005.08.007

Vygotsky, L.S. (1978). Mind in society. Cambridge, MA: Harvard University Press.

Wallhead, T., \& Ntoumanis, N. (2004). Effects of a sport education intervention on students’ motivational responses in physical education. Journal of Teaching in Physical Education, 23, 4-18.

Weiss, M.R., \& Stuntz, C.P. (2004). A little friendly competition: Peer relationships and psychosocial development in youth sport and physical activity contexts. In M.R. Weiss (Ed.), Developmental sport and exercise psychology: A lifespan perspective (pp. 165196). Morgantown, WV: Fitness Information Technology.

Wentzel, K.R. (1999). Social-motivational processes and interpersonal relationships: Implications for understanding motivation at school. Journal of Educational Psychology, 91, 76-97. doi:10.1037/0022-0663.91.1.76

White, S. A. (2007). Parent-created motivational climate. In S. Jowett \& D. Lavallee (Eds.) Social psychology in sport (pp. 131-143). Champaign, IL: Human Kinetics. 
Table 1

Means, Standard Deviations, and Cronbach’s Alpha Coefficients of all Study Variables

\begin{tabular}{lcccccccccc}
\hline & \multicolumn{3}{c}{$\begin{array}{c}\text { Time } 0 \\
(n=262)\end{array}$} & \multicolumn{3}{c}{$\begin{array}{c}\text { Time } 1 \\
(n=233)\end{array}$} & \multicolumn{3}{c}{$\begin{array}{c}\text { Time } 2 \\
(n=147)\end{array}$} \\
\cline { 2 - 11 } Variable & $M$ & $S D$ & $\alpha$ & $M$ & $S D$ & $\alpha$ & $M$ & $S D$ & $\alpha$ \\
\hline Peer-created task climate & 5.55 & .96 & .91 & 5.79 & .86 & .91 & 5.66 & .75 & .92 \\
Peer-created ego climate & 3.95 & .97 & .75 & 3.52 & .91 & .74 & 3.78 & .78 & .71 \\
Coach-created task climate & 4.21 & .62 & .81 & 4.26 & .59 & .86 & 4.02 & .58 & .87 \\
Coach-created ego climate & 2.42 & .79 & .75 & 2.35 & .72 & .74 & 2.68 & .77 & .83 \\
Commitment & 4.21 & .74 & .68 & 4.51 & .59 & .65 & 4.07 & .60 & .63 \\
Respect for conventions & 4.17 & .81 & .71 & 4.15 & .73 & .77 & 4.14 & .66 & .85 \\
Cheating & 2.09 & 1.03 & .80 & 1.92 & .98 & .88 & 2.07 & 1.06 & .86 \\
Gamesmanship & 2.57 & 1.04 & .74 & 2.21 & 1.03 & .84 & 2.35 & 1.12 & .84 \\
Vitality & 5.30 & 1.15 & .89 & 5.40 & .89 & .88 & 5.10 & 1.11 & .93 \\
Burnout & 2.07 & .73 & .90 & 1.77 & .74 & .93 & 1.85 & .84 & .93 \\
Intentions & - & - & - & 1.61 & .91 & .87 & - & - & - \\
Coach-rated effort & 3.74 & .81 & - & 3.15 & .51 & - & 3.34 & .67 & - \\
\hline
\end{tabular}

Note. All variables were measured on 5-point scales with the exception of vitality and peer-created climate, which were measured on 7-point scales. Intentions were measured at one time point and coach-rated effort was assessed using one item. 
Table 2

Regression Coefficients and Standard Errors of the Multilevel Models Exploring Perceptions of the Motivational Climate as Predictors of the

Outcome Variables

\begin{tabular}{|c|c|c|c|c|c|c|c|c|}
\hline & \multicolumn{8}{|c|}{ Outcome Variable } \\
\hline & Cheating & Gamesmanship & Commitment & Conventions & Burnout & Vitality & Coach-rated & Intentions \\
\hline & $\beta(S E)$ & $\beta(S E)$ & $\beta(S E)$ & $\beta(S E)$ & $\beta(S E)$ & $\beta(S E)$ & effort $\beta(S E)$ & $\beta(S E)$ \\
\hline \multicolumn{9}{|l|}{ Intra-individual level } \\
\hline Intercept & $2.02(.08)^{* *}$ & $2.45(.08)^{* *}$ & $4.29(.05)^{* *}$ & $4.13(.06)^{* *}$ & $2.02(.04)^{* *}$ & $5.37(.07)^{* *}$ & $3.69(.09)^{* *}$ & $3.23(.06)^{* *}$ \\
\hline Time & $.01(.05)$ & $-.04(.06)$ & $.02(.05)$ & $.01(.04)$ & $-.15(.05)^{* *}$ & $-.08(.05)$ & $-.21(.08)^{* *}$ & - \\
\hline PC task climate & $-.23(.10)^{*}$ & $-.19(.09)^{*}$ & $.06(.08)$ & $.02(.08)$ & $-.14(.07)^{*}$ & $.13(.12)$ & $-.04(.12)$ & - \\
\hline PC ego climate & $.11(.08)$ & $.22(.08)^{* *}$ & $-.14(.06)^{*}$ & $.06(.07)$ & $.10(.06)$ & $.05(.10)$ & $.02(.10)$ & - \\
\hline CC task climate & $.06(.09)$ & $.00(.09)$ & $.23(.07)^{* *}$ & $.14(.08)$ & $-.03(.07)$ & $.20(.11)$ & $.06(.13)$ & - \\
\hline CC ego climate & $.01(.10)$ & $-.05(.10)$ & $.03(.08)$ & $-.05(.08)$ & $-.09(.07)$ & $.17(.11)$ & $-.08(.13)$ & - \\
\hline PC task climate $\times$ time & $.19(.09)^{*}$ & $.18(.09)^{*}$ & $.09(.07)$ & $.10(.08)$ & $.07(.06)$ & $.08(.11)$ & $-.02(.12)$ & - \\
\hline PC ego climate $\times$ time & $-.11(.08)$ & $-.12(.08)$ & $.04(.06)$ & $-.04(.07)$ & $.01(.05)$ & $-.06(.09)$ & $.00(.11)$ & - \\
\hline CC task climate $\times$ time & $-.07(.09)$ & $.03(.08)$ & $-.01(.06)$ & $-.03(.07)$ & $.00(.06)$ & $.02(.10)$ & $-.08(.13)$ & - \\
\hline
\end{tabular}


COACH AND PEER MOTIVATIONAL CLIMATE 32

\begin{tabular}{|c|c|c|c|c|c|c|c|c|}
\hline CC ego climate $\times$ time & $.21(.09)^{*}$ & $.29(.08)^{* *}$ & $-.09(.06)$ & $.02(.07)$ & $.34(.06)^{* *}$ & $-.15(.10)$ & $.16(.14)$ & - \\
\hline \multicolumn{9}{|l|}{ Inter-individual level } \\
\hline PC task climate & $-.12(.07)$ & $-.05(.08)$ & $.12(.05)^{*}$ & $.11(.06)$ & $-.14(.06)^{*}$ & $.42(.09)^{* *}$ & $.11(.07)$ & $.07(.07)$ \\
\hline PC ego climate & $.12(.07)$ & $.21(.08)^{* *}$ & $-.04(.05)$ & $-.15(.06)^{*}$ & $.11(.06)$ & $-.17(.09)$ & $-.21(.08)^{* *}$ & $-.07(.07)$ \\
\hline CC task climate & $.05(.08)$ & $.02(.08)$ & $.21(.06)^{* *}$ & $.19(.07)^{* *}$ & $-.01(.06)$ & $.28(.10)^{* *}$ & $-.07(.09)$ & $.17(.08)^{*}$ \\
\hline CC ego climate & $.22(.08)^{* *}$ & $.24(.08)^{* *}$ & $-.00(.06)$ & $.02(.07)$ & $.26(.07)^{* *}$ & $.20(.10)^{*}$ & $.08(.08)$ & $-.26(.07) * *$ \\
\hline PC task climate $\times$ time & $.07(.07)$ & $-.00(.06)$ & $-.01(.06)$ & $.05(.06)$ & $.03(.05)$ & $-.07(.09)$ & $-.09(.10)$ & - \\
\hline PC ego climate $\times$ time & $-.02(.06)$ & $-.09(.06)$ & $.02(.05)$ & $.08(.05)$ & $-.07(.05)$ & $-.03(.08)$ & $.06(.09)$ & - \\
\hline CC task climate $\times$ time & $-.01(.07)$ & $.01(.06)$ & $-.04(.05)$ & $-.04(.06)$ & $-.05(.05)$ & $-.08(.09)$ & $.01(.11)$ & - \\
\hline CC ego climate $\times$ time & $.09(.07)$ & $-.01(.06)$ & $-.06(.05)$ & $.02(.06)$ & $.04(.05)$ & $-.09(.09)$ & $-.11(.10)$ & - \\
\hline \multicolumn{9}{|l|}{ Inter-team level } \\
\hline PC task climate & $-.11(.35)$ & $.39(.33)$ & $-.02(.22)$ & $.92(.24)^{* *}$ & $-.48(.18)^{* *}$ & $.32(.30)$ & $.78(.33)^{*}$ & $.12(.10)$ \\
\hline PC ego climate & $.18(.23)$ & $.72(.22)^{* *}$ & $-.15(.15)$ & $.32(.16)^{*}$ & $.09(.13)$ & $-.06(.20)$ & $-.25(.26)$ & $-.06(.10)$ \\
\hline CC task climate & $-.43(.32)$ & $-.28(.31)$ & $.36(.21)$ & $-.13(.22)$ & $-.05(.18)$ & $-.12(.28)$ & $.46(.36)$ & $.21(.09)^{*}$ \\
\hline CC ego climate & $.21(.21)$ & $.18(.20)$ & $.20(.13)$ & $-.15(.15)$ & $-.01(.11)$ & $-.07(.18)$ & $.72(.22)^{*}$ & $-.11(.12)$ \\
\hline PC task climate $\times$ time & $-.09(.23)$ & $-.13(.28)$ & $.12(.23)$ & $-.40(.19)^{*}$ & $-.09(.24)$ & $-.39(.22)$ & $-.74(.30)^{*}$ & - \\
\hline
\end{tabular}


COACH AND PEER MOTIVATIONAL CLIMATE 33

\begin{tabular}{|c|c|c|c|c|c|c|c|}
\hline PC ego climate $\times$ time & $.16(.16)$ & $.10(.20)$ & $.16(.15)$ & $-.18(.13)$ & $.22(.16)$ & $.14(.16)$ & $.35(.25)$ \\
\hline CC task climate $\times$ time & $-.16(.25)$ & $-.24(.30)$ & $-.13(.22)$ & $.32(.19)$ & $-.22(.25)$ & $.41(.24)$ & $-.12(.49)$ \\
\hline CC ego climate $\times$ time & $-.19(.14)$ & $-.22(.17)$ & $-.16(.14)$ & $.10(.12)$ & $-.17(.15)$ & $.04(.14)$ & $-.58(.39)$ \\
\hline
\end{tabular}

Note. $\mathrm{PC}=$ peer-created, $\mathrm{CC}=$ coach-created, $*=p<.05, * *=p<.01$. 